\title{
Utility of Ictal SPECT in the Presurgical Evaluation of Rasmussen's Encephalitis
}

\author{
Jorge G. Burneo, Margaret Hamilton, William Vezina, Andrew Parrent
}

\begin{abstract}
Background: Rasmussen's encephalitis is a progressive disease characterized by severe progressive neurological and cognitive deficits. It is a difficult condition to treat with conventional medical treatment and requires, in most of the cases, surgical intervention. Methods: We present the case of a patient with Rasmussen's encephalitis who presented with epilepsia partialis continua, who did not respond to antiepileptic treatment and was evaluated for possible surgical intervention. Results: The electroencephalographic studies revealed bihemispheric involvement during seizures, although magnetic resonance imaging (MRI) showed a marked right hemispheric atrophy. Hyperperfusion over the right hemisphere was seen with the performance of ictal single photon emission computed tomography (SPECT), which finally guided a right functional hemispherectomy and subsequent seizure control. Conclusion: Ictal SPECT could be a useful tool in the armamentarium of tools used for the localization of the epileptogenic focus in patients with Rasmussen's encephalitis and other localizationrelated epilepsies.
\end{abstract}

RÉSUMÉ: Utilité du SPECT critique dans l'évaluation préopératoire de l'encéphalite de Rasmussen. Contexte: L'encéphalite de Rasmussen est une maladie progressive caractérisée par des déficits neurologiques et cognitifs progressifs sévères. C'est une maladie difficile à traiter médicalement et il faut avoir recours à la chirurgie dans la plupart des cas. Méthodes: Nous présentons le cas d'un patient atteint d'encéphalite de Rasmussen qui a consulté pour une épilepsie partielle continue ne répondant pas au traitement antiépileptique. Il a été évalué en vue d'une chirurgie. Résultats: Les études électroencéphalographiques ont révélé que les deux hémisphères étaient impliqués pendant les crises convulsives, même si l'IRM montrait une atrophie importante de l'hémisphère droit. À la gammatomographie effectuée pendant une crise, on a observé une hyperperfusion de l'hémisphère droit. Le patient a subi une hémisphérectomie fonctionnelle droite qui a entrâné le contrôle de l'épilepsie. Conclusion: La gammatomographie critique pourrait être un outil supplémentaire pour localiser le foyer épileptogène chez les patients atteints d'encéphalite de Rasmussen ainsi que chez des patients atteints d'autres épilepsies dues à un foyer localisé.

Can. J. Neurol. Sci. 2006; 33: 107-110

Rasmussen's encephalitis is a progressive inflammatory disorder of the brain, characterized by difficult to control focal seizures, progressive psychomotor deterioration, manifested by hemiparesis, dysphasia, hemianopia, and cognitive decline. Typically, the disease is confined to one cerebral hemisphere. ${ }^{1-3}$

Even though, on computed tomographic imaging (CT) and magnetic resonance imaging (MRI) there is usually evidence of progressive unilateral cerebral atrophy, and electroencephalography (EEG) usually lateralizes the presence of interictal and ictal epileptiform discharges; ${ }^{2,4-6}$ structural imaging and electrographic findings sometimes may be non-specific. ${ }^{1,7}$

Treatment is difficult because seizures are often resistant to antiepileptic medications. In some cases, steroids, immunoglobulins (IVIg), and plasmapheresis may be useful in early stages of the disease; they have shown no evidence in long term efficacy. ${ }^{8,9}$ Hemispherectomy has shown to provide the best long-term results. ${ }^{1,10,11}$

We report a patient with Rasmussen's encephalitis who underwent an exhaustive evaluation but required additional functional neuroimaging, in the form of single photon emission

From the Epilepsy Programme (JGB, MH, AP), Division of Nuclear Medicine, Department of Radiology (WV), University of Western Ontario, London, ON, Canada. ReCeIVEd July 19, 2005. ACCEPTED IN FINAL FORM OCTOBER 17, 2005. Reprint requests to: Jorge G. Burneo, B10-120, Epilepsy Programme, University of Western Ontario, London Health Sciences Centre, 339 Windermere Road, London, Ontario, N6A 5A5, Canada. 
computed tomography (SPECT), for further lateralization of seizure onset. This lead into a successful surgical treatment.

\section{CASe Report}

A 25-year-old right-handed female, with severe mental retardation, was admitted to the epilepsy unit at London Health Sciences Centre for evaluation of continuous episodes of seizures, of 30-50 seconds of duration, characterized by sudden turn of the head to the left associated with clonic movements of the left upper and lower extremities and left side of the face, followed by turning of the head to the right side and smiling. She was having seven to ten events per day. In some occasions these events were progressing into generalized tonic-clonic seizures. She also had occasional episodes of generalized myoclonic jerks and absences of short duration.

Her past medical history was remarkable for the presence of the seizures since the age of $2 \frac{1}{2}$ years-old and an episode of status epilepticus at the age of $3 \frac{1}{2}$ years-old with subsequent progressive psychomotor delay. Over the years, she had been on ten different anti-epileptic medications without improvement, as well as prednisone and Luteinizing Hormone analogue. She was evaluated in a different institution in January of 1985, and underwent a right temporal lobectomy, without seizure control. Pathology results were not available. She received at least two courses of IV Immunoglobulin months after surgery, with improvement for a short period of time.

On examination upon admission she had left spastic hemiparesis, severe cognitive delay, and exhibited continuous clonic movements of the left upper and lower extremities (Epilepsia partialis continua).

\section{EEG AND MRI}

The patient underwent continuous video-EEG monitoring with electrodes placed according to the International 10-20 system (32-channel XLTEK digital EEG system, Canada) at the London Health Sciences Centre Epilepsy Unit. The interictal EEG recordings revealed multiple independent bi-hemispheric spikes, generalized epileptic recruiting rhythm, and generalized spikes and polyspikes with slow waves; her background was slow. Multiple seizures of the semiology already described were recorded, with evidence of an onset characterized by generalized spikes, followed by $1 / 2$ to one second attenuation of the background and bihemispheric epileptic recruiting rhythm, at times more prominent over the left hemisphere, but without clear lateralization (Figure 1).

Magnetic resonance imaging studies revealed the presence of severe atrophy over the entire right hemisphere (Figure 2).

\section{SPECT}

Due to the lack of lateralization seen in EEG recordings, an ictal SPECT was carried out. The ictal scan followed an injection of 99mTc-hexamethyl-propyleneamineoxime (HMPAO) during one of her seizures (confirmed by simultaneous EEG recordings), and a baseline interictal scan 24 hours later. The ictal study revealed hyperperfusion on the right hemisphere, almost exclusively in the frontal lobe; with evidence of hypoperfusion in the interictal scan (Figure 3).

The interictal SPECT scan was done while the patient was under constant video-EEG monitoring. The interictal injection was performed eight hours after a seizure.

\section{SURGERY AND POSTOPERATIVE COURSE}

The patient underwent a right functional hemispherectomy, which rendered her seizure free immediately after. Her neurological condition did not change as she remained hemiparetic and dysphasic. In a follow-up visit, five months after surgery, the patient's caregiver reported only isolated events of
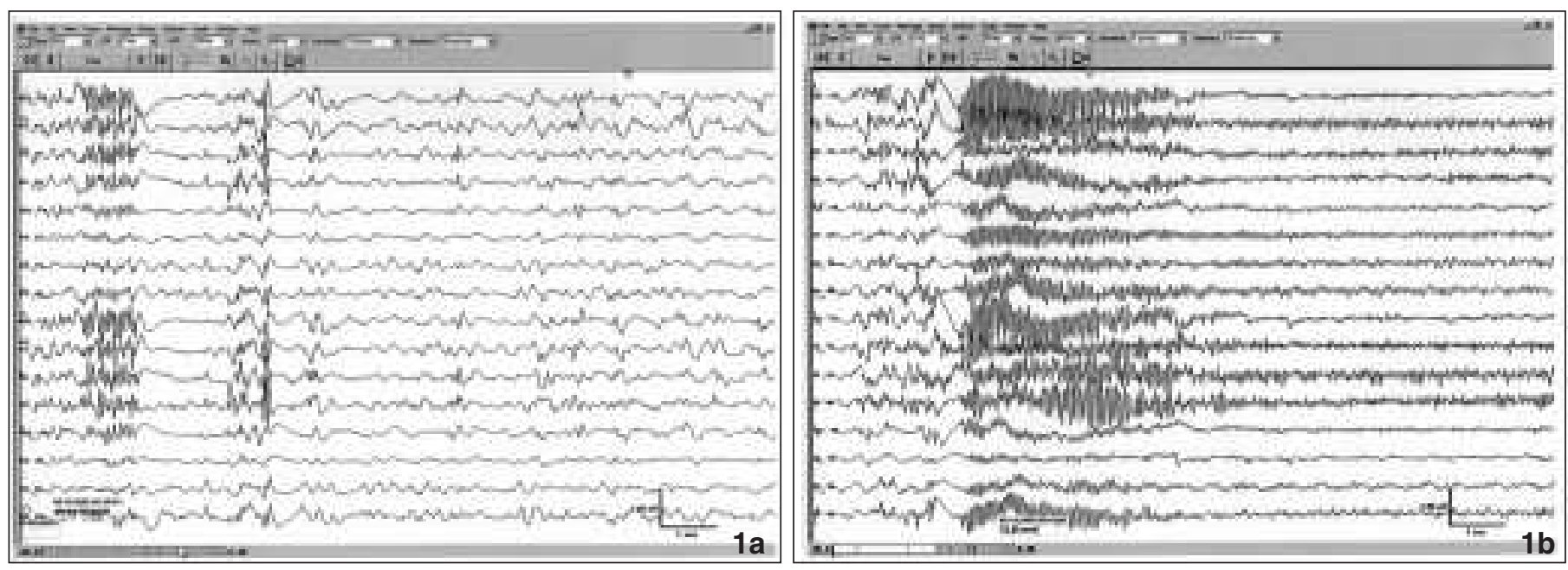

Figure 1: a) Interictal recordings revealed generalized spikes and polyspikes and slow waves (more prominent left), attenuation of background, and slow background. b) Electro-encephalography recordings during a seizure, revealing the presence of generalized polyspikes followed by less than a second attenuation of background and subsequent generalized (more prominent left) recruiting rhythm. The EEG recordings are in bipolar montages ( $L F F 1 \mathrm{~Hz}, \mathrm{HFF} 70 \mathrm{~Hz}$, sensitivity $7 u \mathrm{~V} / \mathrm{mm}$ ). 

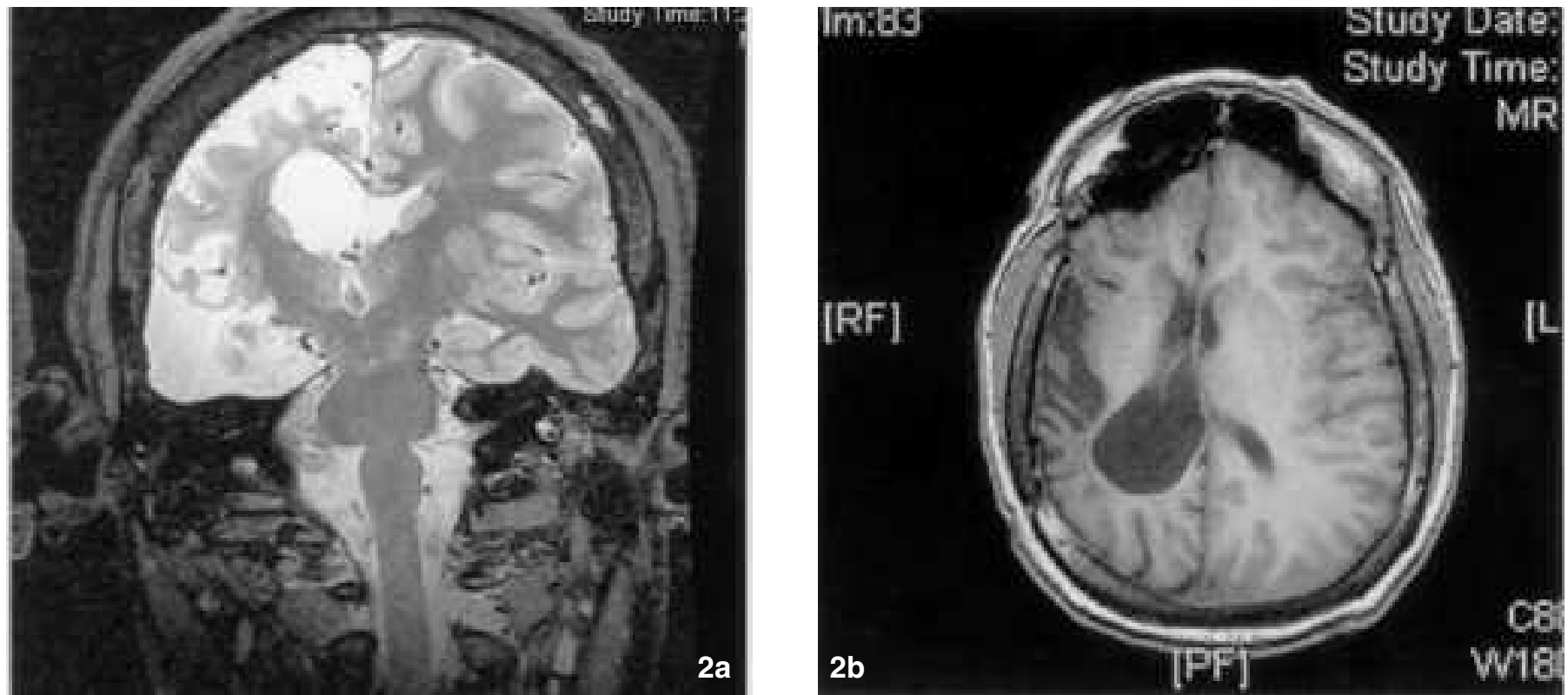

Figure 2: High resolution T2-weighted MRI in coronal section (a) and axial T1 (b), revealing severe atrophy on the right hemisphere, ex-vacuo dilatation of the right lateral ventricle, and absence of the right temporal lobe (status post right temporal lobectomy)

staring spells, of unknown etiology. She has not had similar events to the ones responsible for the admission and subsequent surgery. Pathology report indicated the presence of inflammatory changes and widespread gliosis compatible with the diagnosis of Rasmussen's Encephalitis.

\section{Discussion}

In the most extensive study to date of EEG changes in Rasmussen's encephalitis, ${ }^{7}$ bilateral multiple independent discharges were seen in one third of patients, bilaterally synchronous spike and wave or sharp and slow wave discharges were seen in half of the patients; and even though seizures were strictly localized in early stages, they were more widespread in the later course of illness. ${ }^{1}$

Interictal SPECT has been used in the evaluation of patients with this condition, especially as a marker of extension of disease in early stages. ${ }^{12-15}$ The SPECT studies demonstrate a more extensive area of abnormality than structural neuroimaging studies (i.e. CT and MRI), and with sequential studies, that reveal alteration in the sizes of the defect which correlate with the patients' changing clinical condition. The SPECT imaging in Rasmussen's syndrome may also facilitate anatomical localization of the area of pathology, and may demonstrate a changing pattern in cerebral hypoperfusion. It could also serve as

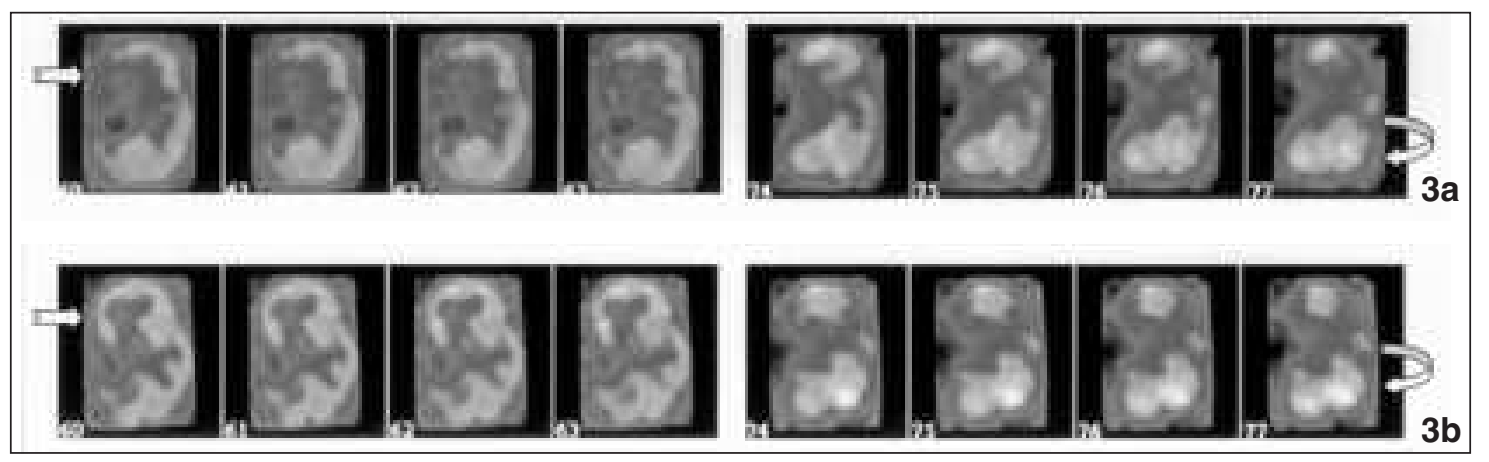

Figure 3: a) Top: Axial interictal SPECT revealing hypoperfusion of the right hemisphere, marked in the frontal and temporal areas. b) Bottom: Ictal SPECT showing hyperperfusion of the right hemisphere, almost exclusively the frontal areas. The right temporal region remained hypoperfused (status post right temporal lobectomy). The straight arrows point to the hypoperfused (top figure), and later hyperperfused right frontal lobe (bottom figure) (Images 60-63). The curved arrows (Images 74-77) points to the contralateral activation (hyperperfusion) of the cerebellum, seen with activation of neocortex in cases of localization-related epilepsy (cerebellar diaschisis). 
a guide to accurate brain biopsy. ${ }^{12}$ Ictal SPECT has also been evaluated in scarce situations, with inconclusive results, that had required the use of other imaging tools. ${ }^{16}$

Our case presents the unique situation in which ictal and interictal SPECT helped with the final decision of performing surgery. Even though the semiology of the epileptic events together with the findings on neurological examination, pointed to a possible right hemispheric onset, EEG recordings did not. The EEG findings confused the picture, especially knowing that Rasmussen's encephalitis may be a disease of both hemispheres. The hypoperfusion seen in the interictal study correlated with the degree of atrophy seen in MRI, but the ictal study was much more helpful for localizing the epileptogenic onset, which mostly involved the frontal region. The usefulness of the study depends a great deal on the time of injection, because a late injection can provide false-localizing results. The advantage of having an epilepsy unit with a bed arrangement in an ICU-like format, allows the nurses to inject the patient faster than having the vial in a monitoring room, outside the patients' area, which would imply more time for the injection of the radioactive agent.

In conclusion, SPECT should be considered as a powerful tool in the armamentarium for lateralization and/or localization of the epileptogenic focus in patients with Rasmussen's encephalitis and all patients undergoing presurgical evaluation.

\section{ACKNOWLEDGEMENTS}

To Bob Vanderwerf for his help with the obtainment and processing of the SPECT images.

\section{REFERENCES}

1. Hart Y, Andermann F. Rasmussen's Syndrome. In: Epilepsy Surgery. Luders HO, Comair YG, editors. Philadelphia: Lippincott Williams \& Wilkins; 2001. p. 145-156.

2. Rasmussen T, Andermann F. Update on the syndrome of "chronic encephalitis" and epilepsy. Cleve Clin J Med. 1989; 56 Suppl Pt 2: S181-4
3. Rasmussen T, Olszewski J, Lloydsmith D. Focal seizures due to chronic localized encephalitis. Neurology. 1958; 8(6): 435-45.

4. Bien CG, et al., Diagnosis and staging of Rasmussen's encephalitis by serial MRI and histopathology. Neurology. 2002. 58(2): p. 250-7.

5. Bien CG, et al. The natural history of Rasmussen's encephalitis. Brain. 2002; 125(Pt 8): 1751-9.

6. Tien RD, et al. Rasmussen's encephalitis: neuroimaging findings in four patients. AJR Am J Roentgenol. 1992; 158(6): 1329-32.

7. So NK, Gloor P. Electroencephalographic and electrocorticographic findings in chronic encephalitis of the Rasmussen type. In: Chronic encephalitis and epilepsy: Rasmussen's syndrome. Andermann F, editor. Boston: Butterworth-Heinemann; 1991. p. 37-45.

8. Hart YM, et al. Medical treatment of Rasmussen's syndrome (chronic encephalitis and epilepsy): effect of high-dose steroids or immunoglobulins in 19 patients. Neurology. 1994; 44(6): 1030-6.

9. Counce D, Limdi N, Kuzniecky R. Rasmussen's Encephalitis. Curr Treat Options Neurol. 2001; 3(6): 555-63.

10. Villemure JG, Andermann F, Rasmussen T. Hemispherectomy for the treatment of epilepsy due to chronic encephalitis. In: Chronic encephalitis and epilepsy: Rasmussen's syndrome. Andermann F, editor. Boston: Butterworth-Heinemann; 1991. p. 235-41.

11. Rasmussen T, Villemure JG. Cerebral hemispherectomy for seizures with hemiplegia. Cleve Clin J Med. 1989; 56 Suppl Pt 1: p. S628; discussion S79-83.

12. English R, et al. Five patients with Rasmussen's syndrome investigated by single-photon-emission computed tomography. Nucl Med Commun. 1989; 10(1): 5-14.

13. Chiapparini L, et al. Diagnostic imaging in 13 cases of Rasmussen's encephalitis: can early MRI suggest the diagnosis? Neuroradiology. 2003; 45(3): 171-83.

14. Paladin F, et al. Utility of Tc 99m HMPAO SPECT in the early diagnosis of Rasmussen's syndrome. Ital J Neurol Sci. 1998; 19(4): 217-20.

15. Burke GJ, Fifer SA, Yoder J. Early detection of Rasmussen's syndrome by brain SPECT imaging. Clin Nucl Med. 1992; 17(9): 730-1.

16. Ishibashi $\mathrm{H}$, et al. Multimodality functional imaging evaluation in a patient with Rasmussen's encephalitis. Brain Dev. 2002; 24(4): 239-44. 